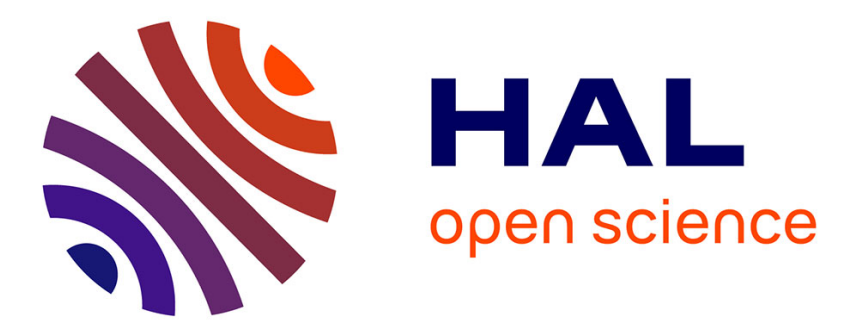

\title{
EFFECTS OF ALLOYING ON THE MAGNETIC AND STRUCTURAL BEHAVIOUR OF CeFe2
}

Sylvaine Roy, S. Kennedy, B. Coles

\section{To cite this version:}

Sylvaine Roy, S. Kennedy, B. Coles. EFFECTS OF ALLOYING ON THE MAGNETIC AND STRUCTURAL BEHAVIOUR OF CeFe2. Journal de Physique Colloques, 1988, 49 (C8), pp.C8271-C8-272. 10.1051/jphyscol:19888120 . jpa-00228264

\section{HAL Id: jpa-00228264 https://hal.science/jpa-00228264}

Submitted on 1 Jan 1988

HAL is a multi-disciplinary open access archive for the deposit and dissemination of scientific research documents, whether they are published or not. The documents may come from teaching and research institutions in France or abroad, or from public or private research centers.
L'archive ouverte pluridisciplinaire HAL, est destinée au dépôt et à la diffusion de documents scientifiques de niveau recherche, publiés ou non, émanant des établissements d'enseignement et de recherche français ou étrangers, des laboratoires publics ou privés. 


\title{
EFFECTS OF ALLOYING ON THE MAGNETIC AND STRUCTURAL BEHAVIOUR $\mathrm{OF} \mathrm{CeFe}_{2}$
}

\author{
S. B. Roy, S. J. Kennedy and B. R. Coles
}

Blackett Laboratory, Imperial College, London, SW7 $2 B Z$, G.B.

\begin{abstract}
Considerable attention has been given to the Laves phase compounds $\mathrm{XFe}$. Two main groups are (a) those where $X$ is a magnetic rare earth element and (b) those where $X$ is non-magnetic and frcm groups III, IV or V (e.g. Y, Zr, $\mathrm{Nb}$, etc.). In many respects $\mathrm{CeFe}_{2}$ seems to belong to the second group but there are interesting structural and magnetic effects when $\mathrm{Co}, \mathrm{Al}, \mathrm{Ru}$, Ir or $\mathrm{Os}$ are substituted for Fe. For all these substitutions ferromagnetism at low temperatures is rapidly lost to be replaced by canted spin structures or antiferromagnetism; and, except for Co, at higher concentrations no ferromagnetism is found at any temperature. The results of recent magnetic, electrical and structural measurements will be discussed in relation to the properties of other $\mathrm{XFe}_{2}$ alloys.
\end{abstract}

Recent experimental studies [1-4] of $\mathrm{CeFe}_{2}$ pseudobinaries have revealed various exotic magnetic phase transitions and stressed the idiosyncracy of the parent compound $\mathrm{CeFe}_{2}$ itself. All these results show that substitution of $\mathrm{Fe}$ by $\mathrm{Al}$, $\mathrm{Co}$ and $\mathrm{Ru}$ is not a simple dilution effect and an instability of the ferromagnetism sets in rapidly on alloying. The highlight of these results is the discovery of a dramatic loss of magnetic response at low temperature with $10 \% \mathrm{Co}$ [2] and $4 \%$ $\mathrm{Ru}$ [4] substitution, which is reminiscent of the ferro to antiferromagnetic transition observed in equiatomic $\mathrm{RhFe}[5]$. In order to shed more light on this subject we have undertaken an intensive magnetic and neutron diffraction study of the effects of alloying on $\mathrm{CeFe}_{2}$. Here we would like to present an outline of the picture which is emerging from this work.

Details of alloy preparation and experimental procedures are described elsewhere $[3,4]$. ac susceptibility results for $\mathrm{Ce}\left(\mathrm{Fe}_{1-x} \mathrm{Ru}_{x}\right)_{2}$ with $0.01 \leq x \leq 0.15$ show a sharp change in slope in $\chi(T)$ for $x=0.02$, as in re-entrant spin-glasses, and by $x=0.04$ this behaviour becomes quite dramatic, suggesting a ferro to antiferromagnetic transition. With increasing $x$, the Curie temperature $\left(T_{\mathrm{c}}\right)$ decreases while the temperature $T_{\mathrm{F}}$ (where the magnetic anomaly appears) starts increasing, and they appear to meet close to $x=0.085$. At first glance the susceptibility behaviour for the alloys with $x \geq 0.09$ appears to be like that of a spin-glass, but the behaviour of the more dilute alloys raises the possibility of fairly extended antiferromagnetic clusters. We hope to solve this problem with further neutron measurements. Whatever may be the nature of the magnetic state for $x \geq 0.09$, be it spin-glass, antiferromagnet or some admixture of the two, it is quite clear that long range ferromagnetism is absent. In figure 1 we show the ac susceptibility results for $x=0.03,0.05$ and 0.09 . The behaviour of $\mathrm{Ce}\left(\mathrm{Fe}_{1-x} \mathrm{Ir}_{x}\right)_{2}$ and $\mathrm{Ce}\left(\mathrm{Fe}_{1-x} \mathrm{Os}_{x}\right)_{2}$ is qualitatively similar to that of $\mathrm{Ce}\left(\mathrm{Fe}_{1-x} \mathrm{Ru}_{x}\right)_{2}$ but there exist some quantitative differences [6]. It is to be no-

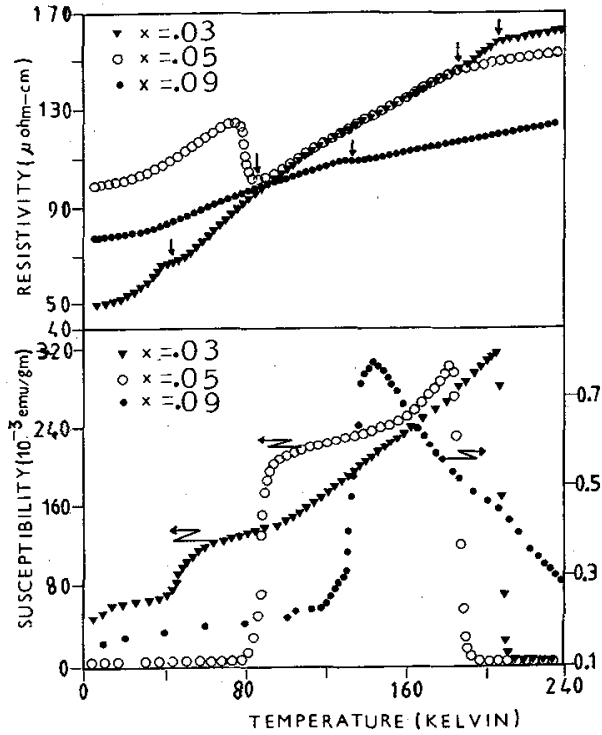

Fig. 1. - ac susceptibility and resistivity vs. temperature for $\mathrm{Ce}\left(\mathrm{Fe}_{1-x} \mathrm{Ru}_{x}\right)_{2} ; x=0.03,0.05,0.09$.

ticed here that, in contrast to $\mathrm{Ce}\left(\mathrm{Fe}_{1-x} \mathrm{Co}_{x}\right)_{2}$ [2], longrange ferromagnetism breaks down totally for a fairly small substitution of $\mathrm{Ru}$, Ir or Os. In a previous paper we reported a tentative magnetic phase diagram for $\mathrm{Ce}\left(\mathrm{Fe}_{1-x} \mathrm{Al}_{x}\right)_{2}$, suggesting a re-entrant spin-glass like behaviour for $x=0.02$ and 0.035 , and spin-glass like behaviour for $x \geq 0.06$. Lately more detailed studies [7] indicate that the phase diagram is much more interesting and around $x=\mathbf{0 . 0 4}$ the system shows a ferro to antiferromagnetic type of transition as with $\mathrm{Ru}, \mathrm{Ir}$ and Os. Now, with hindsight, we even wonder whether alloys with $x \geq 0.06$ are really spin-glasses or whether antiferromagnetism is playing some role here also. Standard dc four probe resistance measurements on various $\mathrm{CeFe}_{2}$ pseudobinaries with $\mathrm{Ru}, \mathrm{Ir}, \mathrm{Os}$ and 
Al show resistivity anomalies which can be correlated with the magnetic anomalies of these systems. In figure 1 we also show resistivity vs. temperature plots for $\mathrm{Ce}\left(\mathrm{Fe}_{1-x} \mathrm{Ru}_{x}\right)_{2}$ with $x=0.03,0.05$ and 0.09 . The character of these resistivity effects varies from system to system as well as in the different concentration regimes [5]. It should be noted here that a similar correlation between resistivity and magnetic behaviour exists in equiatomic $\mathrm{RhFe}$ in the temperature region of the ferro to antiferromagnetic transition.

Our neutron diffraction study on $\mathrm{Ce}\left(\mathrm{Fe}_{1-x} \mathrm{Co}_{x}\right)_{2}$ with $x=0.15$ and 0.2 revealed antiferromagnetic peaks accompanied by a structural distortion from cubic to rhombohedral symmetry [8] at or around the temperature where the magnetic measurements showed the drastic loss of response [2]. Both the antiferromagnetic peaks and the splitting of nuclear Bragg peaks (evidence of structural distortion) could be erased with an applied magnetic field [9], suggesting a metamagnetic behaviour for those systems. A preliminary study of $\mathrm{Ce}\left(\mathrm{Fe}_{0.96} \mathrm{Ru}_{0.4}\right)_{2}$ has shown a similar cubic to rhombohedral distortion which can be correlated with the observed magnetic anomaly. A detailed study of $\mathrm{Ce}\left(\mathrm{Fe}_{1-x} \mathrm{Ru}_{x}\right)_{2}$ is in progress. At this juncture it is to be remembered that $\mathrm{TbFe}_{2}$ and some of its pseudobinaries display similar cubic to rhombohedral distortions, which are related to the spin reorientation and magnetoelastic properties of the system [10]. Though in pure $\mathrm{CeFe}_{2}$ there is indeed some spin reorientation [11], indicating the presence of some sort of anisotropic interaction, until now there has been no indication that the Ce site carries the well localized charge cloud which has to be invoked in the heavy rare earth compounds [10].

Some interesting theoretical work has been done involving the effects of competing anisotropy [12, 13], and reference [13] is particularly interesting in the present context. It reports a Monte Carlo study which took account of competing exchange and anisotropy in a disordered magnetic system and raised the possibility of a very interesting magnetic phase diagram showing ferromagnetism, spin-canting and antiferromagnetism for various values of concentration and temperature. Recent theoretical and experimental work confirms that the magnetism of itinerant electron systems can vary greatly with changes in electronic structure [14]. Hexagonal Laves phase compounds $\left(\mathrm{Hf}_{1-x} \mathrm{Ta}_{x}\right) \mathrm{Fe}_{2}$ show a first order transition from ferro to antiferromagnetism while an interesting co-existence of ferro and antiferromagnetism has been found in $\left(\mathrm{Sc}_{1-x} \mathrm{Ti}_{x}\right) \mathrm{Fe}_{2}$ and $\left(\mathrm{Zr}_{1-x} \mathrm{Nb}_{x}\right) \mathrm{Fe}_{2}$. All these results find a ready explanation in Moriya and Usami's theoretical work [15] on magnetic phase transitions in itinerant electron systems. A recent electronic structure calculation [16] for $\mathrm{CeFe}_{2}$ suggests that here also the magnetism is itinerant in nature, with contributions to magnetization from both iron and cerium.
On this basis one might speculate that the MoriyaUsami theory [15] could be applied to our pseudobinaries based on $\mathrm{CeFe}_{2}$. It should be mentioned here that the observed anomalies in $\mathrm{CeFe}_{2}$ pseudobinaries do not seem to be due to simple disordering effects in the Fe sublattice, since substitution of $\mathrm{Ni}, \mathrm{Rh}, \mathrm{Pd}$ and Pt did not yield any anomalous behaviour, but only a simple dilution effect $[2,6]$. Furthermore Ce appears to be playing a crucial role since substitution by $\mathrm{Y}$ and $\mathrm{U}$ in various $\mathrm{Ce}(\mathrm{Fe}, \mathrm{Co})_{2}$ and $\mathrm{Ce}(\mathrm{Fe}, \mathrm{Al})_{2}$ pseudobinaries depresses the lower transition while raising the Curie temperature [7]. All these observations suggest an intricate relationship between electronic structure and magnetism in $\mathrm{CeFe}_{2}$ and its pseudobinaries, which may well be connected with relationships of effective Ce valency to electron concentration [17].

\section{Acknowledgment}

We acknowledge the loan of precious metals by Johnson Matthey Technology Centre.

[1] Franceschini, D. F. and da Cunha, S. F., J. Magn. Magn. Mater. 52 (1985) 280.

[2] Rastogi, A. K. and Murani, A. P., Proc. 5th Int. Conf. on Valence Fluctuations, Bangalore (Plenum Press, NY) 1987, Eds. L. C. Gupta and S. K. Malik.

[3] Roy, S. B. and Coles, B. R., J. Phys. F 17 (1987) 1215.

[4] Roy, S. B. and Coles, B. R., J. Appl. Phys. 63 (1988) 4094.

[5] Kouvel, J. S. and Hartelius, C. C., J. Appl. Phys. 33 (1962) 1343.

[6] Roy, S. B. and Coles, B. R. (to be published).

[7] Roy, S. B. and Coles, B. R., J. Phys. (Condensed Matter) in press.

[8] Kennedy, S. J., Murani, A. P., Coles, B. R. and Moze, O., J. Phys. F 18 (1988) 2499.

[9] Kennedy, S. J., Murani, A. P., Cockcroft, J. K., Roy, S. B. and Coles, B. R., J. Phys. F (in press).

[10] Clark, A. E., Ferromagnetic Materials, Vol. 1 (E. P. Wohlfarth, North Holland) 1980, p. 531.

[11] Atzmonv, U. and Dariel, M. P., Phys. Rev. B 10 (1976) 2060.

[12] Saslow, W. M., Phys. Rev. B 35 (1987) 3454.

[13] Howard, A. and Gomes, A. A., J. Phys. Soc. Jpn 53 (1984) 4266.

[14] Asano, S. and Ishida, S., J. Phys. F 18 (1988) 501.

[15] Moriya, T. and Usami, K., Solid State Commun. 23 (1977) 955.

[16] Eriksson, O., Nordstrom, L., Brooks, M. S. S. and Johansson, B., Phys. Rev. Lett. 60 (1988) 2523.

[17] Croft, M. et al., Proc. 5th Int. Conf, on Valence Fluctuations, Bangalore (Plenum Press) 1987 , p. 217. 